\title{
Da ocultação à memória difratada: a escrita da resiliência em Palavras cruzadas, de Guiomar de Grammont
}

\author{
From Concealment to Diffracted Memory: The Writing of Resilience \\ in Palavras cruzadas, by Guiomar de Grammont

\section{De la ocultación a la memoria difractada: la escritura de resiliencia} \\ en Palavras cruzadas por Guiomar de Grammont
}

Leonor Lourenço de Abreu*

\section{Resumo}

Neste artigo, pretende-se discutir o percurso de resiliência em face do trauma histórico através da leitura de Palavras cruzadas (2015), de Guiomar de Grammont. O romance exuma as sombras e os fantasmas clandestinos da Guerrilha do Araguaia não só para subtraí-los ao silêncio do esquecimento como para restaurá-los na memória individual e coletiva. Alternando vozes narrativas e tempos históricos diferenciados, perpassa a narrativa a convicção de que o passado que não passa hipoteca o trabalho do luto e criva o presente de culpabilidades não resolvidas. A busca empreendida pela irmã do desaparecido para exorcizar a dor reinveste o percurso deste até o interior da fortaleza verde, flagrando seu ideal utópico face às contradições da luta armada e ao destino trágico dos guerrilheiros.

Palavras-chave: Palavras cruzadas, resiliência, memória, utopia.

\section{Abstract}

This article focuses on a journey of resilience in the wake of historical trauma through a reading of Palavras cruzadas (2015) by Guiomar de Grammont, a novel that unearths the shadows and clandestine phantoms of the Araguaia guerrilla, not only to remove them from silence but also to restore them in the individual and collective memory. Alternating narrative voices with distinct historical temporalities, the narrative is permeated by the conviction that the past that is not past jeopardizes the mourning process and riddles the present with unresolved guilt. The quest undertaken by the disappeared's sister to exorcise the pain of his disappearance revives his journey to the heart of the verdant fortress and reveals his utopian ideal in the face of the contradictions of the armed struggle and the tragic fate of the guerrillas.

Keywords: Palavras cruzadas, resilience, memory, utopia.

\section{Resumen}

En este artículo se pretende discutir el recorrido de resiliencia frente al traumatismo histórico a través de una lectura de Palavras cruzadas (2015), de Guiomar de Grammont, novela que exhuma las sombras y fantasmas clandestinos de la guerrilla de Araguaia, no sólo para sacarlos del silencio, sino para restaurarlos en la memoria individual y colectiva. Alternando voces narrativas y tiempos históricos diversos, la narración sustenta la convicción de que el pasado que no pasa hipoteca el trabajo del duelo y mina el presente de culpabilidades no resueltas. La búsqueda emprendida por la hermana del desaparecido, con el fin de exorcizar el dolor, vuelve a recorrer el camino de este último hasta el corazón de la selva amazónica, y revela su ideal utópico frente a las contradicciones de la lucha armada y del destino trágico de los guerrilleros.

Palabras-clave: Palavras cruzadas, resiliencia, memoria, utopía.

\footnotetext{
*Université Catholique de Louvain, Louvain-la-Neuve, Bélgica. Dorcid.org/0000-0002-5479-6097. E-mail: leonor.deabreu@ uclouvain.be
} 
Sob a história, memória e esquecimento. Sob a memória e o esquecimento, a vida. Mas escrever a vida é outra história. Incompletude.

Paul Ricoeur (2003, p. 657, tradução nossa)

Bem, eu continuarei a remexer esse passado, a pôr a nu as suas feridas purulentas,

para cauterizá-las com o ferro em brasa da memória.

Jorge Semprún (2012, p. 15, tradução nossa)

\section{À prova do esquecimento}

Na Europa, a história traumática do século XX é celebrada em relatos memorialísticos e testemunhais, acadêmicos ou ficcionais, por vezes de forma abusiva, compulsiva e contraditória, incorrendo no risco de banalização como de sacralização, de hiperbolização ou de concorrência das memórias. Essa "onda memorial" conduz ao que Régine Robin (2003), na sequência de Paul Ricoeur (2003), designa por "memória saturada". O Brasil, ao inverso, parece viver uma forma de amnésia oficial, uma "anestesia política", nas palavras de Guiomar de Grammont (2016). O não julgamento dos crimes de responsabilidade ocorridos durante o regime de exceção e a ausência de uma narrativa equânime, isto é, uma justa e objetiva representação do passado recente da Ditadura Militar, com a necessária confrontação das versões e a subsequente "circulação das memórias entre algozes e vítimas" (Robin, 2003), ${ }^{1}$ hipoteca o trabalho do luto, criva o presente de culpabilidades não resolvidas e compromete toda perspectiva de se projetar no futuro.

É sabido que os sistemas totalitários empregam a violência ditatorial e/ou metafórica para infletir os rumos da história a seus ditames político-ideológicos tendo como desígnio uma narrativa nacional homogeneizante. As vozes dissonantes são condenadas ao silenciamento, ao ofuscamento, à amnésia, à morte. A produção literária brasileira atual relacionada com os anos de chumbo ${ }^{2}$ permite exumar tanto o passado recalcado como traumas individuais e coletivos, que aparecem não apenas sob forma de lembrança, mas de convite à ação através da criação artística partilhada. Só assim "a ferida comunitária do país pode vir à tona e ser, se não completamente curada, pelo menos cauterizada, deixando assim de ter o poder hubrístico daquilo que é reprimido" (Lehnen, 2007, p. 89). A necessária passagem da ferida à reabilitação passa por um processo de superação da adversidade, de transmutação, em suma, de resiliência, associado ao topos da esperança, em correlação com o inelutável "trabalho de memória" articulado ao não menos essencial "trabalho de luto" (Ricoeur, 2003, p. 107).

Conceito multidimensional com origem na física (capacidade de um corpo de resistir a um choque - do latim resilio, "saltar") e aplicado ulteriormente ao mundo mental, a resiliência ${ }^{3}$ consiste na faculdade de que dispõem certos indivíduos ou comunidades para fazerem face a episódios dolorosos - traumas históricos, massacres, genocídios - sem abismarem-se na angústia da desagregação, melancolia e morte, e se reconstruírem através de novos projetos, numa dinâmica de reconciliação com a ideia mesmo de existência. Inspirando-se na máxima de Nietzsche, segundo a qual "o que não me mata, me torna mais forte" (Grammont, 2015, p. 93), o neuropsiquiatra francês Boris Cyrulnik, sobrevivente da Shoá, consigna no seguinte axioma a

\footnotetext{
${ }^{1}$ Uma memória justa bem como uma reconciliação completa com o passado não existem em estado puro, antes sinalizam um horizonte utopista.

${ }^{2} \mathrm{O}$ romance francófono oferece igualmente exemplos de produções cuja diegese se situa no período da ditadura, notadamente o escritor francês Jean-Paul Delfino, com Dans l'ombre du condor (2006), e a escritora belga Évelyne Heuffel, com Palmes dans l'azur (2016). O primeiro exibe descrições hiper-realistas de cenas de tortura nos porões do DOPS; a segunda ficcionaliza os pródromos da tragédia que se abaterá sobre uma futura desaparecida.

${ }^{3}$ Atribui-se à psicóloga norte-americana, de origem alemã, Emmy Werner, a autoria, em 1982, do conceito de resiliência.
} 
dimensão ético-ideológica da noção de resiliência: “Dizer a uma vítima que é possível refazer-se psiquicamente não significa relativizar o crime do agressor. Mas quando a vítima cicatriza e consegue transformar a sua dor em luta, o agressor arrisca-se a parecer um pouco menos monstruoso" (Cyrulnik, 2002, p. 21-22, tradução nossa). Associado à atividade artística, o conceito significa uma dinâmica de ressignificação de um acontecimento traumatizante. No campo escritural stricto sensu, a sentença de Isak Dinesen, referida por Hannah Arendt, ilustra a premência da (re)elaboração simbólica como forma de exorcismo dos fantasmas do passado: "As penas, sejam elas quais forem, tornam-se suportáveis se as narrarmos ou fizermos delas uma história" (Arendt, 1994, p. 230). A narração interior não se reverte em sinônimo de retorno do tempo pretérito, antes em emancipação da memória aprisionada nos porões do inconsciente.

\section{Morfologia da memória}

Enquanto no discurso historiográfico existe uma solução de continuidade entre o passado e o presente, implicando uma atitude de distanciamento, na fabulação romanesca - como na elaboração psicanalítica - há um continuum entre o recalcado, o passado de difícil apreensão e as incertezas do presente. O subsídio da ficção literária para a compreensão dos tempos sombrios cumpre um papel heurístico de "suplemento aos arquivos", como bem define Eurídice Figueiredo (2017, p. 29). Afora seu valor documental, por sua própria natureza e seu valor intrínseco, toda criação autônoma desenvolve um poder metaforizador inalienável e libertador enquanto instância formadora e disseminadora de sentido (ou sentidos). Pela possibilidade narrativa de articular dimensões tanto éticas e históricas como afetivas, de mobilizar e representar universos simbólicos, reais e imaginários, a obra de ficção permite "chegar perto da memória e dizer o essencial" (Mavrikakis, 2004, p. 29, tradução nossa). No jogo de clivagens e de fricções com a narrativa histórica, o papel redinamizante da literatura abre o leque dos possíveis, do que não foi, mas poderia ser.

O exercício memorial e escritural no romance Palavras cruzadas revela-se um campo privilegiado onde a experiência traumática da ditadura é restituída através de reminiscências da história pessoal da própria autora, cujo pai morre, como Vladimir Herzog, em 1975, de forma ainda não explicada. Em sua busca para exorcizar a dor, a jornalista Sofia - um alter ego da autora empírica - reinveste o percurso do irmão Leonardo, militante de uma organização clandestina e morto na guerrilha do Araguaia. De maneira, porém, distinta da trama de Prova contrária, de Fernando Bonassi (2003), ${ }^{4}$ os mortos sem sepultura ${ }^{5}$ voltam para assombrar os vivos envolvendo-os na espiral do desastre, hipotecando o seu futuro: "essa falta não permitia que ela [Sofia] construísse nada, nem em sua vida afetiva, nem na profissional. Era uma parede, obstáculo incontornável dentro dela. Tudo que ela tentava empreender em sua vida parecia sugado por esse abismo" (Grammont, 2015, p. 56). A fissura não colmatada é o móbil que conduz a jornalista nas pegadas do irmão, da confortável Belo Horizonte até as paisagens geográfico-mentais de uma Cuba desmitificada e de uma Paris de tons outonais, passando pelas profundezas da floresta amazônica, "magnífica e mortal” (Grammont, 2017, quarta capa), um cenário onde se digladiaram humanidade e desumanidade, e no qual a barbárie se vê ritualmente atualizada, numa circularidade sem fim.

Entre os elementos paratextuais, salientam-se a dedicatória em homenagem às "famílias de todos os desaparecidos políticos do Brasil, sobretudo às suas mães e irmãs" e a epígrafe, extraída de Antígona, de Sófocles: "Seu irmão jazia insepulto; ela não quis que ele fosse espedaçado pelos cães famintos ou pelas aves carniceiras". Configuram ambas orientações de leitura relacionando um contexto histórico particular com a transgressão de um tabu fundador: "Leonardo não morreu. Nenhum corpo foi velado, não houve lágrimas, despedidas ou alma encomendada aos

\footnotetext{
${ }^{4}$ Em que o marido desaparecido ressurge, anos depois, quando a mulher se instala no apartamento adquirido justamente com a indenização providenciada aos familiares das vítimas, ao abrigo da Lei no 9.140 de 1995.

${ }^{5}$ Morts sans sépulture [Mortos sem sepultura] é uma peça de Jean-Paul Sartre escrita em 1941, que encena a resistência francesa através de cinco personagens prisioneiros dos alemães e que, face à tortura, reagirão de maneira ora heróica, ora covarde, ou sucessivamente das duas maneiras.
} 
céus. Leonardo tornou-se uma presença eterna" (Grammont, 2015, p. 56). As trajetórias da protagonista do romance e da heroína trágica encontram-se em posição de homologia estrutural numa relação de intertextualidade assumida: esta viola a lei do Estado, personificado em Creonte, seu tio; a outra transgride a lei do silêncio que se abatera sobre os desaparecidos da ditadura.

Caracterizada por uma descontinuidade narrativa e espaciotemporal própria, alicerçada em técnicas de suspense que a fazem assemelhar-se a um thriller, a malha textual constitui um puzzle de sessenta peças, os sessenta curtos capítulos do livro. As vozes narrativas principais emergem de um discurso autodiegético em forma de diário, da responsabilidade sucessiva do casal de guerrilheiros Mariana e Leonardo. Uma carta do pai e um relato da mãe endereçados ao filho completam o registro autobiográfico. O responsável da enunciação, um narrador onisciente, assume o ponto de vista de Sofia. O romance estrutura-se em dois tempos diegéticos: o tempo da busca - o presente da narração - e o tempo da luta armada contra a ditadura, vinte anos antes. O fio condutor que confere unidade temática à ficção é a urgência da jornalista em conhecer a verdade sobre a trajetória do irmão Leonardo, desaparecido quando ela era ainda criança: necessitava achar o "ponto final [...] que pudesse acabar com aquela suspensão" (Grammont, 2015, p. 167).

O fio de Ariadne configurado na busca - a quête - de Sofia compõe uma teia engendrada em meio às sequelas da desaparição, que assolam os seus pais: angústia, sentimento de culpa, medo e vergonha, transmitidos e interiorizados pela protagonista. Nessa constelação que alia sentimentos contraditórios para exprimir o indizível, é a própria mãe, leitora voraz de romances e poeta ignota, que se institui como o elemento detonador do mecanismo ficcional, pois lembrar-se não é apenas um ato de memória. É um ato de criação. Em outras palavras, existe na construção romanesca uma forma de mise en abyme: a luta por conhecimento de Sofia - nome intrinsecamente motivado - é desencadeada e condicionada por uma estratégia elaborada por Luisa, para que sua filha empreenda a ação e desate os nós que ligam irremediavelmente passado e presente, desaparecimento e busca. Paira no ar um sentimento trágico causado pela presença-ausência dos mortos-vivos, que implica em um estado de "suspensão", isto é, uma moratória só solúvel na morte física - ou simbólica. Se a dor da espera e a expiação da culpa eram o que fazia viver Luisa, a convicção de que o "jogo de esconde-esconde" com o desaparecido (Grammont, 2015, p. 236) atingira o seu ponto final ressuma na aceitação tácita da morte do filho, em sua própria libertação definitiva, bem como na paz recuperada por Sofia, consubstanciada na revelação da identidade de Cíntia/Luisa, a filha do casal de guerrilheiros. A encenação sutil da dialética da vida e da morte encontra aqui o seu ápice, denotando uma construção oximorística da ficção romanesca.

De acordo com a vulgata narratológica, o título de um romance tem por função - ou funções - três aspetos dinamizantes: a "designação", a "indicação do conteúdo" e a "sedução do público" (Genette, 1987, p. 73). Palavras cruzadas é um título semanticamente ativo: sugere uma construção criteriosa e descontínua, um jogo de reflexão, onde nada é deixado ao acaso: os espaços em branco - as lacunas narrativas - serão progressivamente preenchidos por letras, falas, cartas, relatos, diálogos. Em termos funcionais, o título constitui um "limiar", uma "moldura". Situa-se em zona de fronteira, uma zona não apenas de "transição", mas igualmente de "transação" (Genette, 1987, p. 8) para a construção de sentidos. Na tradução francesa (Grammont, 2017), Les ombres de l'Araguaia induz outro tipo de polissemia: além da ressonância exótica do topônimo "Araguaia", o sintagma verbal privilegia a imagem das coisas fugidias, irreais e mutantes, como a alma, o espírito desencarnado, o fantasma. Em outras palavras, são espectros alimentados por segredos do passado que vêm atormentar os indivíduos e os grupos sociais. A dimensão onírica e movediça introduzida pelo título estabelece uma relação de contiguidade metafórica que reverbera na ilustração mesmo da capa: uma floresta tropical em preto e branco. A redução cromática parece sinalizar um espaço no qual não haviam ainda se apartado os mundos da luz e das trevas, ${ }^{6}$ do conhecimento e da ignorância. A predominância

\footnotetext{
${ }^{6}$ Tal ilação vê-se na operação tradutológica do seguinte sintagma: "não tinha a menor ideia de onde estava. Só havia $o$ escuro" (Grammont, 2015, p. 11) em “je n'avais aucune idée d'où je me trouvais. Il n'y avait autour de moi que les ténèbres" (Grammont, 2017, p. 15). Enquanto o "escuro" (le noir) é meramente denotativo, em francês assume uma conotação de tenebroso, abissal, caótico.
} 
dos tons de cinza evidencia uma contaminação semântica ao relacionar o desaparecimento dos guerrilheiros do Araguaia com "aquilo que resta após a extinção do fogo [...], resíduo do corpo depois que nele se extinguiu o fogo da vida" (Chevalier e Gheerbrant, 1990, p. 247).

Enquanto o tropismo (do exotismo) tropical surge desconstruído na edição francesa, a edição brasileira parece, ao contrário, renová-lo. Os elementos visuais da capa - uma mulher na contraluz contempla um pôr do sol aquático - projetam uma imagem de vitalidade serena, porventura melancólica. Assim é que os elementos paratextuais de primordial importância que são as capas exercem forte apelo visual e contribuem para desvelar a ideologia do texto e seu sistema de significações. Aparentemente antagônicos, ambos os paratextos se encontram intrinsecamente ligados; são mutuamente dependentes e dialeticamente complementares.

\section{A violência totalitária}

Partimos do pressuposto que o regime militar que se instalou em 1964 no Brasil reúne caraterísticas dos sistemas totalitários que vigoraram na Europa do século XX, cujo paradigma são o nazifascismo, por um lado, e o comunismo (estalinista), por outro. Ele difere, no entanto, em grau, destas formas extremas da ditadura moderna. O estado totalitário pretende controlar e regular a totalidade da vida pública e privada do indivíduo: "é o Estado, e não mais a humanidade, que detém a medida do bem e do mal; que decide, por conseguinte, em qual direção evoluirá a sociedade" (Todorov, 1994, p. 138, tradução nossa). A ordem impessoal subjuga toda autonomia da pessoa, conduzindo à degradação não só do sujeito como das relações interpessoais (Todorov, 2000, p. 25).

Se Palavras cruzadas tematiza a questão da violência sob a ditadura e a ruptura da legalidade constitucional, não existe, no entanto, uma voz - ou vozes narrativas - portadora do discurso totalitário stricto sensu. Em contrapartida, o poder despótico, esse estende seus tentáculos até os confins da Amazônia, disseminando o terror sobre camponeses e trabalhadores rurais, alienando indígenas e caboclos. As marcas do totalitarismo convertem-se em ações, repertoriadas em perseguição, humilhação, torturas psíquicas e físicas, em corpos supliciados. O sujeito totalitário apropria-se assim do corpo dos guerrilheiros, o inimigo interno - o "subversivo", o "terrorista" - que deve ser exterminado: "ser classificado como inimigo é suficiente para excluí-lo da humanidade" (Todorov, 1994, p. 191). A despersonalização do inimigo implica em seu aniquilamento total, do apagamento civil à ocultação ontológica e ao silenciamento histórico. Assim é que, ulteriormente, os corpos das vítimas serão exumados e reduzidos a cinzas jogadas a esmo no abismo: "na história extraoficial e confidencial do país, tinha acabado a guerrilha do Araguaia" (Lisboa, 2012, p. 223).

O incipit do romance, dinâmico, projeta de imediato o leitor in medias res: "Parece um sonho agora" (Grammont, 2015, p. 9). Marcada por um movimento descensional, de efeito dramático seguro, a abertura aponta para um clima onírico de irrealidade. As fronteiras das categorias espaciotemporais se dissolvem, anunciando a desagregação dos projetos utopistas dos guerrilheiros: "o mato cresce nas picadas abertas. As feridas tornam-se cicatrizes, irão desaparecer. Como os nomes" (Grammont, 2015, p. 9). Como as armas e munições, "agora completamente enferrujadas e inúteis, como se falassem da falta de sentido de toda aquela guerra" (Grammont, 2015, p. 44).

A voz narrativa responsável dos onze primeiros capítulos encena a derrocada subjetiva e objetiva do guerrilheiro Leonardo, após as incursões militares que exterminaram um a um os membros do grupo de combatentes, como os camponeses suspeitos de colaboração com a guerrilha. O sonho revolucionário de libertação dos camponeses através de uma guerra popular exauriu-se. Sobra um campo de ruínas, espaço de regressão do universo pós-utópico no qual a degenerescência dos ideais contamina os próprios objetos. Antes protetora, uma "segunda mãe!" (Lisboa, 2012, p. 97), a floresta funciona agora como coadjuvante das forças repressoras - "a mata se torna delatora" (Grammont, 2015, p. 113) -, numa relação de contiguidade significante com os caboclos e bate-paus, cooptados e forçados a detectar os foragidos que nela buscaram abrigo e proteção. A perseguição do exército com a sua reiteração dos massacres reduz o 
inimigo à "pura imanência, como um bicho" acuado (Grammont, 2015, p. 18). O cerco que se fecha em torno do guerrilheiro exangue como um fantasma, e vítima de alucinações, atualiza, no espaço dos confins, a experiência concentracionária dos campos de extermínio nazistas. $\mathrm{O}$ compromisso ético e moral com a luta acha-se proporcionalmente diminuído, como a indicar a inutilidade de tudo. A precariedade existencial absoluta impossibilita qualquer laivo de heroísmo e reduz o indivíduo a uma forma de "negatividade constitutiva" tanto individual como histórica (Costa, 2016, p. 40).

A ilusão lírica - o entusiasmo revolucionário para a realização de um ideal - foi de curta duração, remetendo aos tempos áureos da instalação na selva, quando a vida encontrou alguma promessa de harmonia, de plenitude: "nossa universidade é essa gente, essa mata, esse chão" (Grammont, 2015, p. 102). A polarização semântica em torno da noção de irreversibilidade - o caminho sem volta - acentua a dimensão trágica da guerrilha a braços com a questão da exequibilidade histórica. O questionamento da perspectiva revolucionária - o dogmatismo apaixonado -, que o romance tematiza, imprime à obra um caráter crítico. Assim é que a composição dos personagens guerrilheiros Leonardo e Mariana denota a ambivalência destes em razão do contexto histórico e das aporias da própria luta armada.

Os seres de papel de Grammont são, à partida, personagens fortes e abnegados, que rompem com uma sociedade acomodada e amedrontada. Porém, em vez de super-heróis, são seres com aspirações comuns - viver um grande amor, ter filho(s) - que se deixam aspirar pelo turbilhão da história até o ponto de não retorno. $O$ ponto de não retorno que arrasta Leonardo na engrenagem é justamente aquele que pode ser considerado como o auge do processo de iniciação: o justiçamento do companheiro delator ou suspeito de fraqueza ideológica. Esse crime coletivo, que lança "a mãe no abismo da culpa" (Grammont, 2015, p. 219), provoca a transformação do "eu" (Leonardo) em "outro" (Antônio), uma sombra, posto que portador de uma máscara identitária. Mariana ressente essa metamorfose como sob o efeito de um estado segundo: a execução das ações práticas cria "um efeito de hiper-realidade, ausência de passado e de futuro. Só existe o presente, vamos apagando devagar tudo que fomos" (Grammont, 2015, p. 72). $O$ apagamento gradual redunda num processo de transfiguração similar àquele narrado pelo escritor cubano Leonardo Padura no romance El hombre que amaba a los perros. $\mathrm{O}$ personagem Ramón Mercader - futuro assassino do revolucionário soviético Leon Trótski, exilado no México - passa por um processo ritual de aprendizagem ao termo do qual "sentiu muito nitidamente que estava se transformando em fantasma sem nome, sem bússola, sem caminho de retorno" (Padura, 2011, p. 285, tradução nossa).

A caracterização do personagem da guerrilheira reflete os dilemas e tensões da luta na selva e confere ao combate a sua dimensão feminina. Mariana representa a vida em contexto de morte - a maternidade potencia a simbólica vital. A sua experiência oscila entre céu e inferno, esperança e desesperança, num cenário de claros-escuros. Autêntica consciência antecipadora da distopia militante, ela ressente o seu mundo pessoal - e amoroso - se dissolver na experiência coletiva. A projeção no futuro, como a projeção no imaginário, lhe são vedadas. $O$ seu itinerário é marcado pela presciência da perseguição e da morte, como se a ideologia totalitária contaminasse tanto a natureza ambiente como o próprio microcosmo representado pela comunidade revolucionária - do interior da fortaleza verde à selva de pedra de São Paulo.

Embora não escamoteie a responsabilidade da violência revolucionária praticada pelas organizações envolvidas na luta armada, Palavras cruzadas realça o abuso odioso e o sadismo pela força, as marcas constitutivas dos agentes da repressão, cujo modus operandi é intercambiável, posto que inserido numa lógica dicotômica do bem e do mal. A configuração dos personagens representantes do regime obsceno tem encontrado resistências por parte da crítica. Assim é que Costa (2016, p. 41) questiona "o processo de humanização do militar em plena caçada aos guerrilheiros": um soldado expressa emoção ao recordar os filhos; um outro cede um lápis ao prisioneiro enquanto aguarda instruções. O caso de construção simbólica mais polêmico por sua ambiguidade profunda diz respeito ao coronel do exército, responsável pelas operações de massacre deliberado no Araguaia. Além de comandar o processo de extermínio e de "adotar" a filha do casal morto, o militar manda encaminhar o diário dos guerrilheiros aos 
pais de Leonardo. Vítima de um ataque, o sujeito totalitário vegeta numa cadeira de rodas, atormentado e condenado ao silêncio, como um "arquivo morto" (Grammont, 2015, p. 187).

As atrocidades cometidas no século XX logram propiciar a indagação de como pessoas normais, bons maridos e pais de família podem ter sido responsáveis pela materialização do "mal extremo". A tentação consiste em tachá-los de monstros e projetá-los fora da humanidade. Em sua formulação narrativa, Palavras cruzadas assume uma postura ética que se aproxima da perspectiva de Hannah Arendt e de testemunhas diretas do holocausto nazista, como Primo Levi: "Os monstros existem, mas eles são muito pouco numerosos para serem realmente perigosos; os mais perigosos são os homens comuns" (Todorov, 1994, p. 133, tradução nossa). O "mal extremo", propiciado por seres prontos a obedecer e a agir sem questionar, em vez de ser um mal radical, isto é inumano, acaba sendo, paradoxalmente, banal, no quadro de sobredeterminações de ordem política e social, que subsumem as motivações psicológicas e individuais - sem exonerarem o indivíduo da sua responsabilidade legal e moral.

\section{Nos meandros da memória e do esquecimento}

O romance Palavras cruzadas inscreve-se numa dinâmica discursiva ligada a uma ética memorial com a finalidade de driblar o risco do esquecimento. A encenação narrativa permite compensar a ausência de um espaço funerário, a fim de preservar a memória das vítimas, dos sobreviventes e das famílias. Duas estratégias ficcionais possibilitam recriar simbolicamente esse espaço de transação que permita o trabalho do luto. A primeira situa-se em posição central (capítulo XXXI): Sofia viaja no interior da mata e é conduzida ao local onde ocorrera a incineração dos corpos dos guerrilheiros, uma clareira dando para um abismo: "A vegetação ondulada, lá embaixo, parecia convidá-la a pular. As lágrimas escorriam por sua face. - Deus te proteja [...] Se é que um dia você esteve aqui, mano. Os corpos nunca foram devolvidos às famílias" (Grammont, 2015, p. 127). A segunda consiste na entrega do diário à família do guerrilheiro. Em parte reescrito pelo próprio coronel do exército porque as letras estavam desaparecendo, este caderno representa um sucedâneo do corpo do desaparecido. Recria-se assim uma espécie de cerimônia de potlatch, no quadro de um ritual de trocas simbólicas desiguais - ligando as duas partes.

A subjetividade da autora empírica perpassa na experiência romanesca, marcada por determinações pessoais e pelo poder performativo da linguagem. A porosidade entre as esferas do ficcional e da realidade permite uma melhor apreensão da história, tornando-a inteligível para além dos traumatismos engendrados. A ambição totalizadora do romance é visível, tanto do ponto de vista intratextual - romance(s) no romance -, como do ponto de vista discursivo, com uma preocupação de didatismo, quando se propõe a discutir as noções de anistia - similar a "amnésia", "esquecimento institucional" (Ricoeur, 2003, p. 586) -, esquecimento e perdão desenvolvidas por Arendt e Ricoeur: "Só a narrativa e a memória, ou seja, a revisão do passado, permitiriam o perdão. Seria preciso recontar a história com os olhos do presente, para exorcizar a dor" (Grammont, 2015, p. 174). Se bem que pertinentes e legítimos, estes elementos propiciam as chaves de leitura, atenuando o alcance do romance ao bloquear a indeterminação enquanto possibilidade estética. A literatura não se pretende demonstrativa, antes deve perseguir o insondável.

A busca de Sofia pode se resumir na "escolha de Sofia", do romance Sophie's Choice, de William Styron, publicado em 1979: significa uma escolha trágica e insustentável entre duas possibilidades viver/sofrer. Não há solução ideal. No plano narrativo, não há reparação (o reconhecimento do crime e o pedido de perdão); o algoz morre em silêncio embora tenha, de certa forma, tentado expiar a sua culpa. As considerações morais são de ordem individual e constituem uma solução provisória; como todo movimento de diástole e de sístole, representam uma necessidade vital que não prejulga o andamento da história. A fabulação romanesca inscreve a possibilidade de um ponto de fuga: a criança, hoje adulta, que possibilita a reconciliação. 
A mediação da escrita representa, para Leonardo, a única forma de não enlouquecer; para Mariana, a possibilidade de conjurar o mal e de se erguer acima das contingências, a fim de dar voz a um movimento sem memória. Para Guiomar de Grammont, "escrever sobre o drama da perda, vivido por ela [Sofia] em cumplicidade com a mãe, me ajudou [...] a lidar com essa falta, teve um efeito redentor, ainda que não catártico" (Grammont, 2016). A despeito de um estilo por vezes repetitivo e tentado pelo páthos; apesar de algumas demonstrações retóricas e edificantes, Palavras cruzadas é certamente uma fábula, que pretende discutir a superação de uma herança traumática para a elevar à condição de emblema. Uma etapa possível no caminho da redenção?

O percurso de resiliência que subjaz à construção narrativa de Grammont indica uma postura ética embasada na ideologia da tolerância. Denota um tom conciliatório e apaziguante, esvaziando, segundo Kucinski, o debate em torno da responsabilização e da justiça: "ficou-me a sensação de que Palavras Cruzadas iguala na crítica comportamental guerrilheiros e repressores, soldados e mateiros, lavradores e batedores, como se a floresta, na sua rudeza, a todos nivelasse. Poderia contrapor citando Primo Levi: "Os dois estão na mesma armadilha, mas é o opressor e só ele quem a preparou e a fez disparar" (Kucinski, 2015). Palavras cruzadas não é, certamente, um livro "revisionista" ou "negacionista", como denuncia Costa (2016); sua escrita oximorística revela os mistérios insondáveis da alma humana e contribui para restaurar "a voz das vítimas silenciadas dos massacres" (Vecchi, 2014, p. 141). Partindo da premissa que só o pedido de perdão permite o perdão, e que só este pode desatar os nós, assinala Paul Ricoeur: "Cabe à justiça extrair das lembranças traumatizantes o seu valor exemplar e transformar a memória em projeto; é esse mesmo projeto de justiça que confere ao dever de memória a forma do futuro e do imperativo" (Ricoeur, 2003, p. 107, tradução nossa).

Para concluir, assinale-se que, se no que tange à memória individual, a construção romanesca oferece uma resposta concebível, em relação à memória coletiva de que a história é o vetor principal, tal visão corre o risco da simplificação em relação ao peso da exterminação e do vazio ontológico. O romance foge, porém, ao binarismo culpado/inocente; antes negocia um meio termo - a terceira margem - entre vitimismo e liberdade assumida, buscando explorar os meandros recônditos do recalcado num processo que vai da dilaceração psíquica à reabilitação ontológica, nos antípodas de qualquer lógica dicotômica.

\section{Referências}

ARENDT, Hannah (1994). Condition de l'homme moderne. Tradução de Georges Fradier. Prefácio de Paul Ricœur. Paris: Calmann-Lévy; Pocket.

BONASSI, Fernando (2003). Prova contrária. Rio de Janeiro: Objetiva.

CHEVALIER, Jean; GHEERBRANT, Alain (1990). Dicionário de símbolos. Tradução de Vera da Costa e Silva et al. Rio de Janeiro: José Olympio.

COSTA, Carlos Augusto Carneiro (2016). Ficção e guerrilha do Araguaia: elementos revisionistas no romance Palavras cruzadas de Guiomar de Grammont. Literatura e autoritarismo. Santa Maria, v. 16, p. 35-48, mar. Disponível em: https:// periodicos.ufsm.br/LA/article/view/21503/13026. Acesso em: 15 out. 2018.

CYRULNIK, Boris (2002). Un merveilleux malheur. Paris: Odile Jacob.

FIGUEIREDO, Eurídice (2017). A literatura como arquivo da ditadura brasileira. Rio de Janeiro: 7Letras.

GENETTE, Gérard (1987). Seuils. Paris: Éditions du Seuil.

GRAMMONT, Guiomar (2015). Palavras cruzadas. Rio de Janeiro: Rocco.

GRAMMONT, Guiomar (2016). Guiomar de Grammont e as palavras que se cruzam. [Entrevista concedida a] Tiago Ribeiro. Mafuá. Florianópolis, n. 25. Disponível em: https://bit.ly/2UqZy1h. Acesso em: 10 set. 2019.

GRAMMONT, Guiomar de (2017). Les ombres de l'Araguaia. Traduzido por Danielle Schramm. Paris: Métailié. 
KUCINSKI, Bernardo (2015). "Palavras cruzadas" revela crueldade da guerrilha do Araguaia. O Estado de S. Paulo, São Paulo, 26 set. Disponível em: https:// bit.ly/2xz5TyC. Acesso em: 30 ago. 2019.

LEHNEN, Leila (2007). O retorno do reprimido: ditadura, memória e capital em Prova contrária, de Fernando Bonassi. Caderno de Letras da UFF, n. 33, p. 87-103. Disponível em: https://bit.ly/3bDRbVE. Acesso em: 21 jan. 2020.

LISBOA, Adriana (2012). Azul corvo. Lisboa: Quetzal Editores.

MAVRIKAKIS, Catherine (2004). Nos mnémosynes modernes. Spirale, Montreal, n. 194, p. 28-29, jan./fev. Disponível em: https://id.erudit.org/iderudit/18374ac. Acesso em: 13 set. 2019.

PADURA, Leonardo (2011). L'homme qui aimait les chiens. Tradução de René Solis e Elena Zayas. Paris: Métailié.

RICOEUR, Paul (2003). La mémoire, l'histoire, l'oubli. Paris: Seuil.

ROBIN, Régine (2003). Présences du passé. In: ROBIN, Régine. La mémoire saturée. Paris: Stock. Disponível em: https:// bit.ly/2UqgaGi. Acesso em: 13 set. 2019.

SEMPRÚN, Jorge (2012). Le fer rouge de la mémoire. Paris: Gallimard.

TODOROV, Tzvetan (1994). Face à l'extrême. Paris: Seuil.

TODOROV, Tzvetan (2000). Mémoire du mal tentation du bien. Paris: Robert Laffont.

VECCHI, Roberto (2014). O passado subtraído da desaparição forçada: Araguaia como palimpsesto. Estudos de Literatura Brasileira Contemporânea, Brasília, n. 43, p. 133-139, jan./jun. Disponível em: https:// bit.ly/3aFmxvn. Acesso em: 30 out. 2018. 